\title{
Chemotherapy and Radiotherapy Downregulate the Activity and Expression of DNA Methyltransferase and Enhance Bcl-2/E1B- 19-kDa Interacting Protein-3-Induced Apoptosis in Human Colorectal Cancer Cells
}

\author{
Qian Deng $^{\mathrm{a}}$ Chun-mei Huang ${ }^{\mathrm{a}} \mathrm{Ni} \mathrm{Chen}^{\mathrm{b}}$ Li Li $^{\mathrm{c}}$ Xiao-dong Wang ${ }^{\mathrm{c}}$ \\ Wen Zhang ${ }^{c}$ Feng $\mathrm{Bi}^{\mathrm{a}}{ }^{\mathrm{e}}$ Qiu-lin Tang ${ }^{\mathrm{e}}$ Zhi-ping $\mathrm{Li}^{\mathrm{a}}$ Wei Wang ${ }^{d}$ \\ ${ }^{a}$ Department of Abdomen Oncology, Cancer Center of West China Hospital, West China Medical School, Sichuan \\ University, Departments of ${ }^{\mathrm{b}}$ Pathology, ${ }^{\mathrm{C}}$ Colorectal Surgery and ${ }^{\mathrm{d}}$ Neurosurgery, and ${ }^{\mathrm{e}}$ State Key Laboratory of \\ Signal Transduction and Molecular Targeting Therapy, West China Hospital, West China Medical School, Sichuan \\ University, Chengdu, PR China
}

\section{Key Words \\ Colorectal cancer - Chemotherapy · Radiotherapy - BNIP3 · \\ DNA methyltransferase}

\begin{abstract}
$\mathrm{Bcl}-2 / \mathrm{E} 1 \mathrm{~B} 19-\mathrm{kDa}$ interacting protein 3 (BNIP3) is a proapoptotic protein whose expression level is often low in colorectal cancer (CRC) cells due to the BNIP3 gene promoter DNA methylation by DNA methyltransferase (DNMT). It is known that chemotherapy and radiotherapy suppress CRC through inducing tumor apoptosis. However, the molecular mechanisms underlying chemotherapy and radiotherapy-induced apoptosis of CRC cells are not well defined. In this study, we observed that the expression level of BNIP3 in colon cancer cells was significantly increased by treatment with therapeutic agents and radiation in vitro. The BNIP3 protein level in CRC tissues from patients who received preoperative concurrent chemotherapy was significantly higher than in those who received surgery alone. Furthermore, treatment with chemotherapeutic agents and radiation significantly decreased the DNMT1 expression level and enzymatic ac-
\end{abstract}

\section{KARGER}

Fax +4161306 1234

E-Mail karger@karger.ch

www.karger.com
(C) 2013 S. Karger AG, Basel

0009-3157/13/0586-0445\$38.00/0

Accessible online at:

www.karger.com/che tivity. Both expression level and activity of DNMT1 were inversely correlated with the expression level of BNIP3 in coIon carcinoma cells after treatment with chemotherapeutic agents and radiation. Consistent with increased BNIP3 expression, chemotherapeutic agents and radiation induced colon carcinoma cell apoptosis in a dose-dependent manner. Based on these observations, we conclude that chemotherapy and radiotherapy inhibit DNMT1 expression to upregulate BNIP3 expression to promote CRC cell apoptosis. And, BNIP3 may play a role in the caspase-dependent apoptosis pathways, mainly during treatment with chemotherapy and radiotherapy.

Copyright $\odot 2013$ S. Karger AG, Basel

\section{Introduction}

Colorectal cancer (CRC), including colon and rectal cancers, is one of the most common malignant tumors worldwide, with about one million new cases each year (accounting for $9.4 \%$ of all new tumors) and approximately 50,000 deaths. Along with their rapid economic 
development, China, Japan and South Korea have seen an increasing incidence over the last 30-40 years [1].

Adjuvant chemotherapy is a standard treatment for CRC, whereas radiotherapy is highly suitable for the treatment of rectal cancer, but is not yet recommended as a standard treatment for colon cancers. Apoptosis is the predominant mechanism of cell death induced by chemotherapy and radiation treatments [2]. The regulation of apoptosis is a delicate and complex process, and two major genes - p53 and Bcl-2 - have been demonstrated to be involved in this process.

As a member of the Bcl-2 family of proteins, the proapoptotic protein BNIP3 (Bcl-2/E1B 19-kDa interacting protein 3 ) has received significant research interest in recent years. BNIP3 is a mitochondrial protein that interacts with the E1B 19-kDa adenovirus protein and Bcl-2 [3, 4]. BINP3 is highly expressed in human breast, lung and cervical cancers, but is absent in many other tumors such as colorectal, gastric, pancreatic and hematopoietic tumors [5]. The lack of BNIP3 expression is attributed to abnormal methylation and histone acetylation of its 5VCPG sequence domain in the promoter region. This block of expression is controlled by DNA methyltransferase (DNMT) [6], as the use of a DNMT inhibitor, 5-aza-dC, can remove this suppression and restore the expression of BNIP3, thus inducing cells to undergo apoptosis [7].

Therefore, we considered that the expression of BNIP3 might be upregulated via inhibition of DNMT following treatment with chemotherapy and radiotherapy, thus inducing apoptosis in CRC cells.

\section{Materials and Methods}

\section{Reagents}

Mouse monoclonal anti-BNIP3 antibodies and rhodamine 123 (Rh123) were purchased from Sigma (St. Louis, Mo., USA). Rabbit monoclonal anti-Bax antibodies were purchased from Cell Signaling Technology (USA). Mouse polyclonal anti- $\beta$-actin antibodies were purchased from Boster (Wuhan, PR China). Horseradish peroxidase-labeled donkey anti-mouse IgG was purchased from Gene Company (Hong Kong, SAR, China). All synthesized primers were from Invitrogen (Carlsbad, Calif., USA). RPMI-1640 powder, calf serum and trypsin were products of Gibco (Grand Island, N.Y., USA). Chemotherapeutics included 5-flurouracil (5FU) from Tianjin Jinhui Pharmaceutical (Tianjin, PR China) and oxaliplatin (L-OHP) and irinotecan (CPT-11) from Jiangsu Hengrui Medicine (Jiangsu, PR China).

\section{Cell Culture}

The human colon cancer cell line SW480 was a gift from the Laboratory of Signal Transduction and Molecular Targeting Therapy of Huaxi Medical School, Sichuan University, PR China. Cells were grown as adherent, single-layer cultures in RPMI-1640 supplemented with $10 \%$ calf serum at $37^{\circ} \mathrm{C}$ in a humidified atmosphere consisting of $5 \% \mathrm{CO}_{2}$ and $95 \%$ air.

\section{In vitro Experimental Design}

At the logarithmic growth phase, cells were treated using an $\mathrm{X}$ linear accelerator with a $6-\mathrm{MeV}$ and $4-\mathrm{Gy} / \mathrm{min}$ dose rate. 5 - FU, LOHP and CPT-11 were all dissolved in sterile deionized water at a concentration of 192, 12.6 and $5.9 \mathrm{mmol} / \mathrm{l}$, respectively, and stored at $-20^{\circ} \mathrm{C}$. Stock solutions were diluted to the desired final concentrations with growth medium just before use. The low concentration group includes $0.038 \mathrm{mmol} / \mathrm{l}$ of $5-\mathrm{FU}, 0.00075 \mathrm{mmol} / \mathrm{l}$ of CPT11 and $0.0005 \mathrm{mmo} / \mathrm{l}$ of L-OHP. The high concentration group includes $0.076 \mathrm{mmol} / \mathrm{l}$ of 5 -FU, $0.0015 \mathrm{mmol} / \mathrm{l}$ of CPT-11 and 0.0176 $\mathrm{mmol} / \mathrm{l}$ of L-OHP. Cultures were divided into three dosage groups (group A, B and C), and each of these was treated with one of three different therapies: radiotherapy alone, chemotherapy alone, or concurrent chemotherapy (CCR). The experiments were repeated several times. In group $A$, the dosage of both radiotherapy and chemotherapy was 0 . In group B, the dosage of radiotherapy was $2 \mathrm{~Gy}$ and chemotherapy included the low concentration as mentioned above, while the dosage of CCR was $2 \mathrm{~Gy}$ and the low concentration. In group $\mathrm{C}$, the dosage of radiotherapy was $4 \mathrm{~Gy}$ and chemotherapy included the high concentration as mentioned above, while the dosage of CCR was $4 \mathrm{~Gy}$ and the high concentration.

The SW480 cells were allocated into 6-well culture plates $(1 \times$ $10^{5}$ cells $/ \mathrm{ml}$ ), and after $24 \mathrm{~h}$, the cells were treated with chemotherapy and/or radiotherapy and assayed after another $48 \mathrm{~h}$.

\section{Western Blot Analysis}

Cells were added with $500 \mu \mathrm{l}$ cell lysis buffer, frozen and thawed repeatedly with $37^{\circ} \mathrm{C}$ water bath and liquid nitrogen for 3 times, then mixed and determined for protein concentration. Protein samples $(50 \mu \mathrm{g}$ each) were separated via $5-10 \%$ sodium dodecyl sulfate polyacrylamide gel electrophoresis and then electrotransferred onto polyvinylidene fluoride membranes (Millipore, Billerica, Mass., USA). The membranes were allowed to react with primary and secondary antibodies at optimum dilutions, and the immunoreactive signals were detected using an infrared laser scanning system (LI-COR, Lincoln, Nebr., USA) and analyzed by densitometry analysis [8].

\section{Reverse-Transcription PCR}

Total RNA was isolated from cells using TRIzol Reagent (Invitrogen), following the manufacturer's instructions. First-strand cDNA was synthesized from $0.5 \mu \mathrm{g}$ of total RNA using an RNA PCR kit (TaKaRa Bio, Shiga, Japan), following the manufacturer's instructions. The produced cDNAs were then amplified by PCR using the following primers: BNIP3 sense $5^{\prime}$-TCGCAGACACCACAAGATACCAAC-3', BNIP3 antisense 5'-GCAAATGAGAGAGCAGCAGAGATG-3'; DNMT1 sense $5^{\prime}$-ACCTGATCAAGTTTATTGCAGCC-3', DNMT1 antisense $5^{\prime}$-TGGTAGCACATATAGAAGGGCA- $3^{\prime} ; \beta$-actinsense, $5^{\prime}$-TGGAGAAATATGGCACCAC $-3^{\prime}$, and $\beta$-actin antisense $5^{\prime}$ - GAGGCGTACAGGGATAGCAC- ${ }^{\prime}$ [9].

\section{${ }^{3} \mathrm{H}$ Microassays}

${ }^{3} \mathrm{H}$ microassays were carried out as previously described [10]. Protein was prepared as Western blot, and $5 \mu \mathrm{g}$ of protein was incubated for $2 \mathrm{~h}$ at $37^{\circ} \mathrm{C}$ with $11.1 \times 10^{4} \mathrm{~Bq}$ high specific activity 


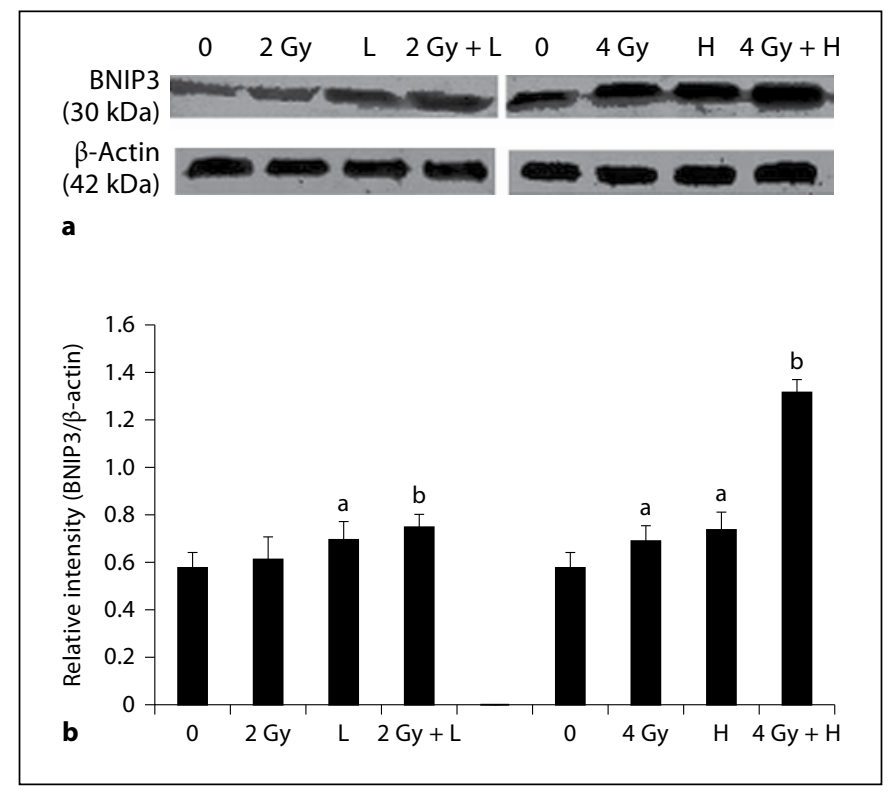

Fig. 1. Western blot analysis of BNIP3. L = Low concentration group of chemotherapy; $\mathrm{H}=$ high concentration group of chemotherapy. a Levels of BNIP3 in SW480 cells after $48 \mathrm{~h}$ of exposure to different doses of chemotherapy and/or radiotherapy. b Data are presented as means $\pm S D(n=3)$. Difference was considered statistically significant when ${ }^{\mathrm{a}} \mathrm{p}<0.05$ and ${ }^{\mathrm{b}} \mathrm{p}<0.01$ versus control.

${ }^{3} \mathrm{H}$-S-adenosylmethionine (Perkin Elmer, Waltham, Mass., USA) and $0.5 \mu \mathrm{g}$ poly[d(I-C)d(I-C)] (Sigma) in a volume of $23 \mu \mathrm{l}$. The signal strength of each sample was determined relative to a control sample. The activity of DNMT was determined as the sample counts per minute relative to the control. SW480 cells treated with non-poly $[\mathrm{d}(\mathrm{I}-\mathrm{C}) \mathrm{d}(\mathrm{I}-\mathrm{C})]$ served as the control.

\section{Apoptosis Assay}

Apoptosis was determined based on morphologic changes and by staining with an annexin V-FITC and propidium iodide (PI) double-labeling kit purchased from Nanjing Biotechnology (Nanjing, PR China), following the manufacturer's instructions [11].

\section{Measurement of Mitochondrial Membrane Potential}

As an index to determine mitochondrial dysfunction, mitochondrial membrane potential (MMP) was monitored using Rh123 [12]. Cells were treated with chemotherapy and/or radiotherapy at the indicated concentration for $48 \mathrm{~h}$ in a 6-well culture plate at $1 \times 10^{5}$ cells $/ \mathrm{ml}$. The medium was then removed and washed three times with serum-free RPMI-1640 medium followed by incubation in fresh serum-free medium containing $1 \mathrm{mg} / \mathrm{l}$ $\mathrm{Rh} 123$ at $37^{\circ} \mathrm{C}$ in the dark for $30 \mathrm{~min}$. Finally, the cells were collected and washed twice with PBS and then analyzed by a FACScan flow cytometer (Becton Dickinson, Franklin Lakes, N.J., USA).

\section{Immunohistochemistry}

A total of 47 tissue specimens from patients with CRC who had undergone either surgery alone, preoperative chemotherapy or preoperative CCR between 2006 and 2009 were identified retrospectively. Nine patients were given radiation treatment over a

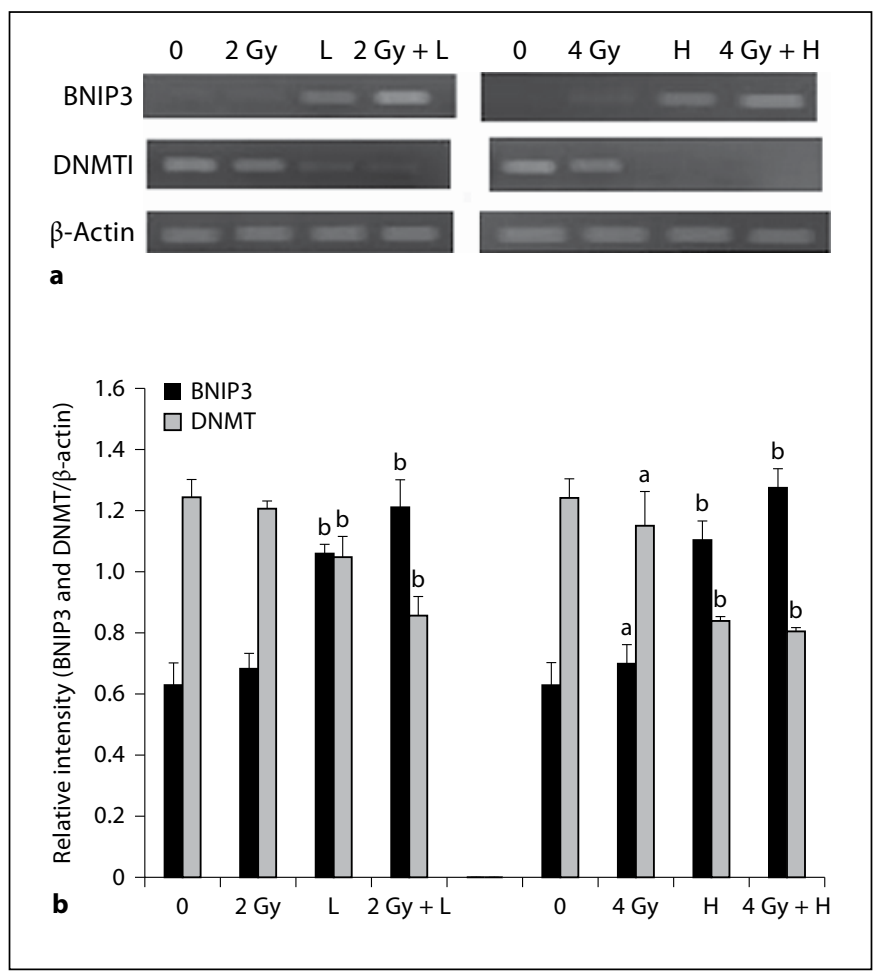

Fig. 2. RT-PCR analysis of BNIP3 and DNMT1. L = Low concentration group of chemotherapy; $\mathrm{H}=$ high concentration group of chemotherapy. a mRNA levels of BNIP3 and DNMT1 in SW480 cells after $48 \mathrm{~h}$ of exposure to different doses of chemotherapy and/ or radiotherapy. $\mathbf{b}$ Data are presented as means $\pm \mathrm{SD}(\mathrm{n}=3)$. Difference was considered statistically significant when ${ }^{\mathrm{a}} \mathrm{p}<0.05$ and ${ }^{\mathrm{b}} \mathrm{p}<0.01$ versus control.

4-week period, with a total of $45 \mathrm{~Gy}$ administered in 20 fractions. Chemotherapy was performed concurrently in weekly doses of 2,800-3,400 mg/m $\mathrm{m}^{2}$ 5-FU, $200 \mathrm{mg} / \mathrm{m}^{2}$ leucovorin and $180 \mathrm{mg} / \mathrm{m}^{2}$ CPT-11 (FOLFIRI) or $1,000 \mathrm{mg} / \mathrm{m}^{2} 5$-FU, $200 \mathrm{mg} / \mathrm{m}^{2}$ leucovorin and $85 \mathrm{mg} / \mathrm{m}^{2} \mathrm{~L}-\mathrm{OHP}$ (FLOFOX4) or L-OHP $130 \mathrm{mg} / \mathrm{m}^{2}$ on day 1 and Xeloda $1,000 \mathrm{mg} / \mathrm{m}^{2}$, twice daily, postoperatively, on days 1-4 (27 patients).

Surgery was performed 4-6 weeks after the cessation of radiotherapy and/or chemotherapy. All specimens were continuously cut into 5 - $\mu \mathrm{m}$-thick sections.

For immunohistochemical staining of the BNIP3 protein, sections were detected using an Envision kit (Dako, Glostrup, Denmark), following the manufacturer's instructions. The negative control for protein staining was the omission of the primary antibody. Expression of the BNIP3 protein was quantified using a visual grading system based on the intensity of staining (graded on a scale of $0-3$ : 0 , no staining; 1 , weak staining; 2 , moderate staining; 3 , strong staining).

\section{Statistical Methods}

Analysis of variance and t tests were used to compare different means. All analyses were performed using SPSS 13.0 software for Windows (SPSS, Chicago, Ill., USA). A p value $<0.05$ was regarded as statistically significant. 
Fig. 3. Immunohistochemical staining of the BNIP3 protein in CRC $(1: 1,000)$. a No expression of BNIP3 (grade 0). b Low expression of BNIP3: cytoplasmic staining (grade 1). c High expression of BNIP3: cytoplasmic staining (grade 2). d Highest expression of BNIP3: cytoplasmic staining (grade 3).
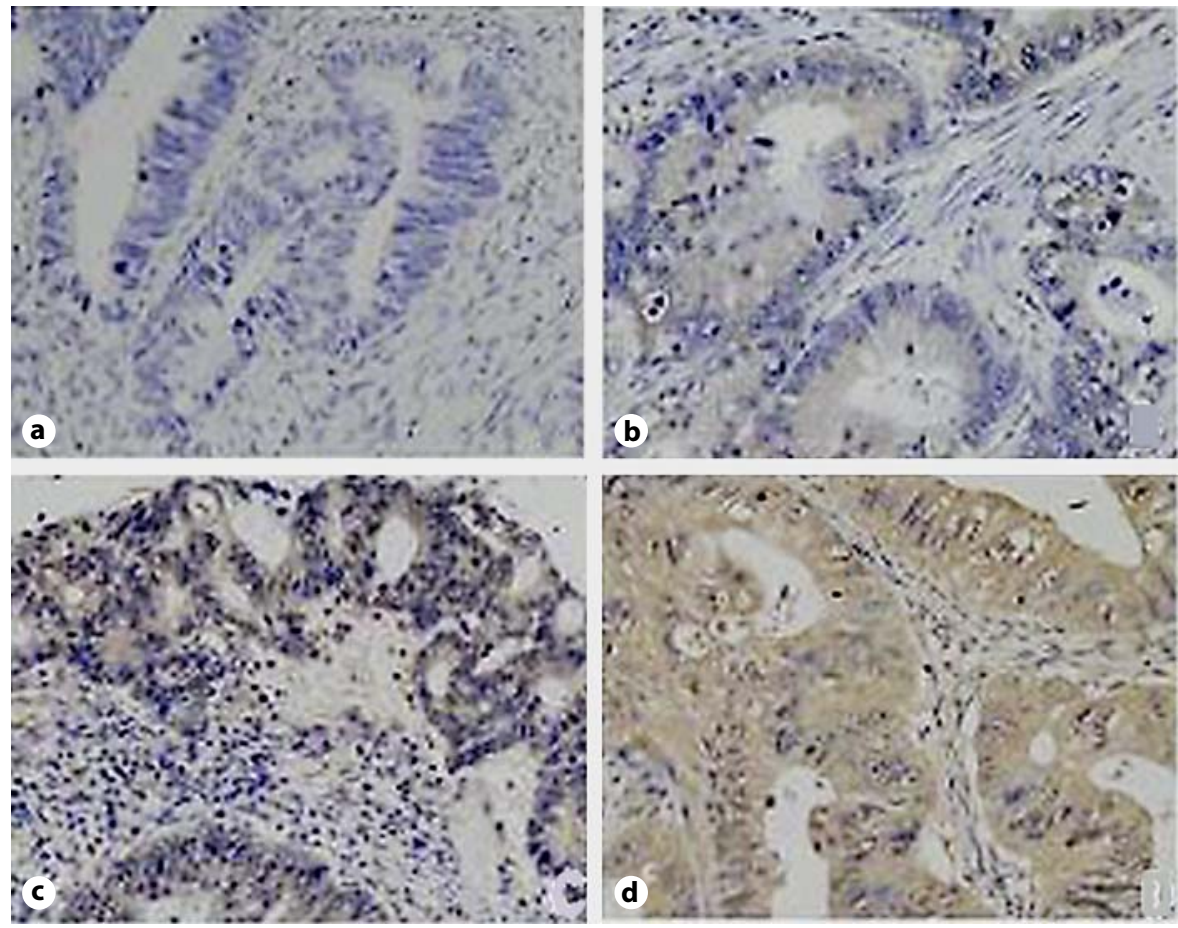

Table 1. Cytoplasmic BNIP3 protein expression in CRC tissues

\begin{tabular}{|c|c|c|c|c|c|c|}
\hline \multirow[t]{2}{*}{ Therapy } & \multicolumn{2}{|l|}{ Total } & \multicolumn{4}{|c|}{ Grade of staining } \\
\hline & + & - & 0 & 1 & 2 & 3 \\
\hline Surgery $(n=20)$ & $13(0.65)$ & $7(0.35)$ & $7(0.35)$ & $9(0.45)$ & $2(0.1)$ & $2(0.1)$ \\
\hline Preoperative chemotherapy $(n=18)$ & $17(0.94)^{*}$ & $1(0.06)$ & $1(0.06)$ & $5(0.28)$ & $9(0.5)^{*}$ & $3(0.17)$ \\
\hline Preoperative CCR $(n=9)$ & $8(0.89)^{\star *}$ & $1(0.11)$ & $1(0.11)$ & $5(0.56)$ & $3(0.33)^{*}$ & $5(0.11)$ \\
\hline
\end{tabular}

Figures in parentheses are percentages. ${ }^{\star} \mathrm{p}<0.01$ and ${ }^{\star *} \mathrm{p}<0.05$, compared with surgery.

\section{Results}

Expression of BNIP3 in Colon Cancer Cells and CRC Tissues following Chemotherapy and/or Radiotherapy

BNIP3 levels were assayed in vitro by Western blot and RT-PCR. BNIP3 protein expression in tissues from patients with CRC following three different kinds of therapy, including surgery, preoperative chemotherapy and preoperative CCR, was assessed by immunohistochemistry.

BNIP3 protein expression in colon cancer cells following radiotherapy and/or chemotherapy was significantly higher than in the untreated control cells $(\mathrm{p}<0.05)$, with the exception of radiotherapy alone at $2 \mathrm{~Gy}(\mathrm{p}=0.233)$. BNIP3 expression was highest following CCR, which was notably better than chemotherapy or radiotherapy alone $(p<0.05)$. As the dose of CCR increased, the increased expression of BNIP3 became more apparent $(p<0.05)$, but there were no obvious differences between the radiotherapy and chemotherapy treatment groups $(\mathrm{p}=0.162$ and 0.312 , respectively; fig. 1 ).

BNIP3 mRNA levels in colon cancer cells following radiotherapy and/or chemotherapy were significantly higher than in the untreated control cells $(\mathrm{p}<0.05)$, with the exception of radiotherapy alone at 2 Gy $(p>0.05)$. BNIP3 mRNA levels were highest following CCR, which was notably better than radiotherapy or chemotherapy alone $(\mathrm{p}<0.05)$. As the dose of CCR was increased, no obvious change in expression was observed ( $p>0.05$; fig. 2). 
The positive rate of BNIP3 protein staining in CRC tissues from patients receiving preoperative CCR was significantly higher than in those from patients who received only surgery $(p<0.05)$ but showed no relation to those from patients who received only preoperative chemotherapy ( $p>0.05$; fig. 3 ; table 1$)$.

\section{Expression of DNMT1 in Colon Cancer Cells following} Chemotherapy and/or Radiotherapy

The in vitro expression of DNMT1 at the transcriptional level and enzymatic activity were tested by RT-PCR and ${ }^{3} \mathrm{H}$ microassays, respectively. The expression of DNMT1 in colon cancer cells following radiotherapy and/or chemotherapy was significantly lower than in the untreated control cells $(\mathrm{p}<0.05)$, with the exception of radiotherapy alone at $2 \mathrm{~Gy}(\mathrm{p}>0.05)$. This expression was the lowest following CCR, which was significantly lower than in cells of patients receiving radiotherapy alone $(\mathrm{p}<$ 0.05 ). As the dose of CCR was increased, no obvious change in expression was observed ( $p>0.05$; fig. 2 ).

The activity of DNMT1 in colon cancer cells following radiotherapy and/or chemotherapy was significantly lower than in the untreated control cells $(\mathrm{p}<0.05)$. This activity was the lowest following treatment with CCR, which was significantly less than in cells of patients treated with radiotherapy or chemotherapy alone $(\mathrm{p}<0.05)$. As the dose of CCR was increased, no obvious increase in activity was observed $(\mathrm{p}>0.05)$. There were no clear differences in DNMT1 activity between the radiotherapy and chemotherapy groups $(\mathrm{p}>0.05$; table 2).

\section{Expression of Bax in Colon Cancer Cells following}

\section{Chemotherapy and/or Radiotherapy}

Bax protein expression in colon cancer cells following chemotherapy and CCR was significantly lower than in the untreated control cells $(\mathrm{p}<0.05)$. Bax expression was lowest following CCR, which was notably lower than chemotherapy or radiotherapy alone $(\mathrm{p}<0.01)$. However, as the dose of CCR was increased, no obvious difference in activity was observed ( $p>0.05)$, and there were no obvious differences between the radiotherapy and chemotherapy treatment groups ( $\mathrm{p}>0.05$; fig. 4 ).

\section{Effect of Chemotherapy and/or Radiotherapy on Apoptosis of Colon Cancer Cells}

The in vitro apoptotic rate of colon cells was tested by flow cytometry. The apoptotic rate following radiotherapy and/or chemotherapy was significantly higher than in the untreated control cells $(\mathrm{p}<0.05)$. As the treatment

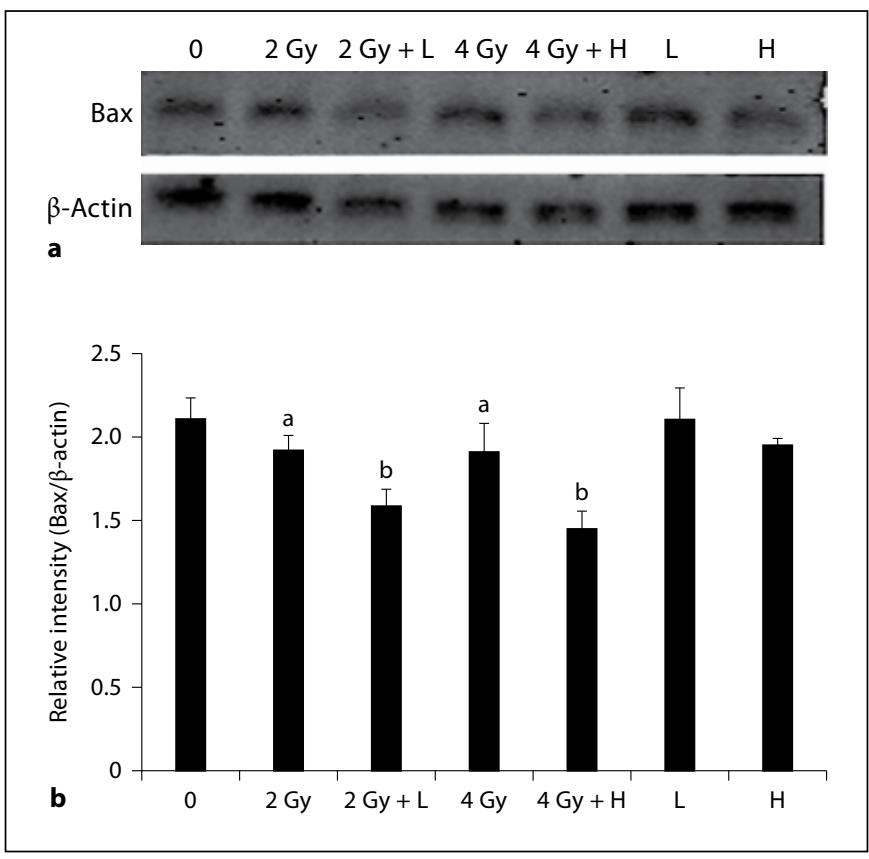

Fig. 4. Western blot analysis of Bax. $\mathrm{L}=$ Low concentration group of chemotherapy; $\mathrm{H}=$ high concentration group of chemotherapy. a Levels of Bax in SW480 cells after $48 \mathrm{~h}$ of exposure to different doses of chemotherapy and/or radiotherapy. $\mathbf{b}$ Data are presented as means $\pm \mathrm{SD}(\mathrm{n}=3)$. Difference was considered statistically significant when ${ }^{\mathrm{a}} \mathrm{p}<0.05$ and ${ }^{\mathrm{b}} \mathrm{p}<0.01$ versus control.

Table 2. DNMT activity in colon cancer SW 480 cells by radiotherapy and chemotherapy

\begin{tabular}{llll}
\hline Group & DNMT & & \\
\cline { 2 - 4 } & radiotherapy & chemotherapy & CCR \\
\hline A & $2.5012 \pm 0.12459$ & $2.5012 \pm 0.12459$ & $2.5012 \pm 0.12459$ \\
B & $2.0764 \pm 0.16187$ & $1.9744 \pm 0.11595$ & $1.5080 \pm 0.15723^{\mathrm{c}}$ \\
C & $2.0626 \pm 0.16119^{\mathrm{a}}$ & $1.9564 \pm 0.15865^{\mathrm{b}}$ & $1.4064 \pm 0.15725^{\mathrm{c}}$ \\
\hline
\end{tabular}

${ }^{\mathrm{a}} \mathrm{p}<0.05$ and ${ }^{\mathrm{b}} \mathrm{p}<0.01$, compared with group A. ${ }^{\mathrm{c}} \mathrm{p}<0.05$, compared with group $\mathrm{B} / \mathrm{C}$.

dose was increased, the apoptotic cells increased accordingly $(\mathrm{p}<0.01)$, with the exception of those cells treated with chemotherapy alone $(\mathrm{p}=0.351)$. There were significant differences in apoptotic cells among the three interventions ( $\mathrm{p}<0.05$; fig. 5 ).

\section{Chemotherpy and/or Radiotherapy-Induced Loss of $M M P$ in CRC Cells}

To assess the effect of chemotherapy and/or radiotherapy on the changes of MMP in CRC cells, flow cyto- 


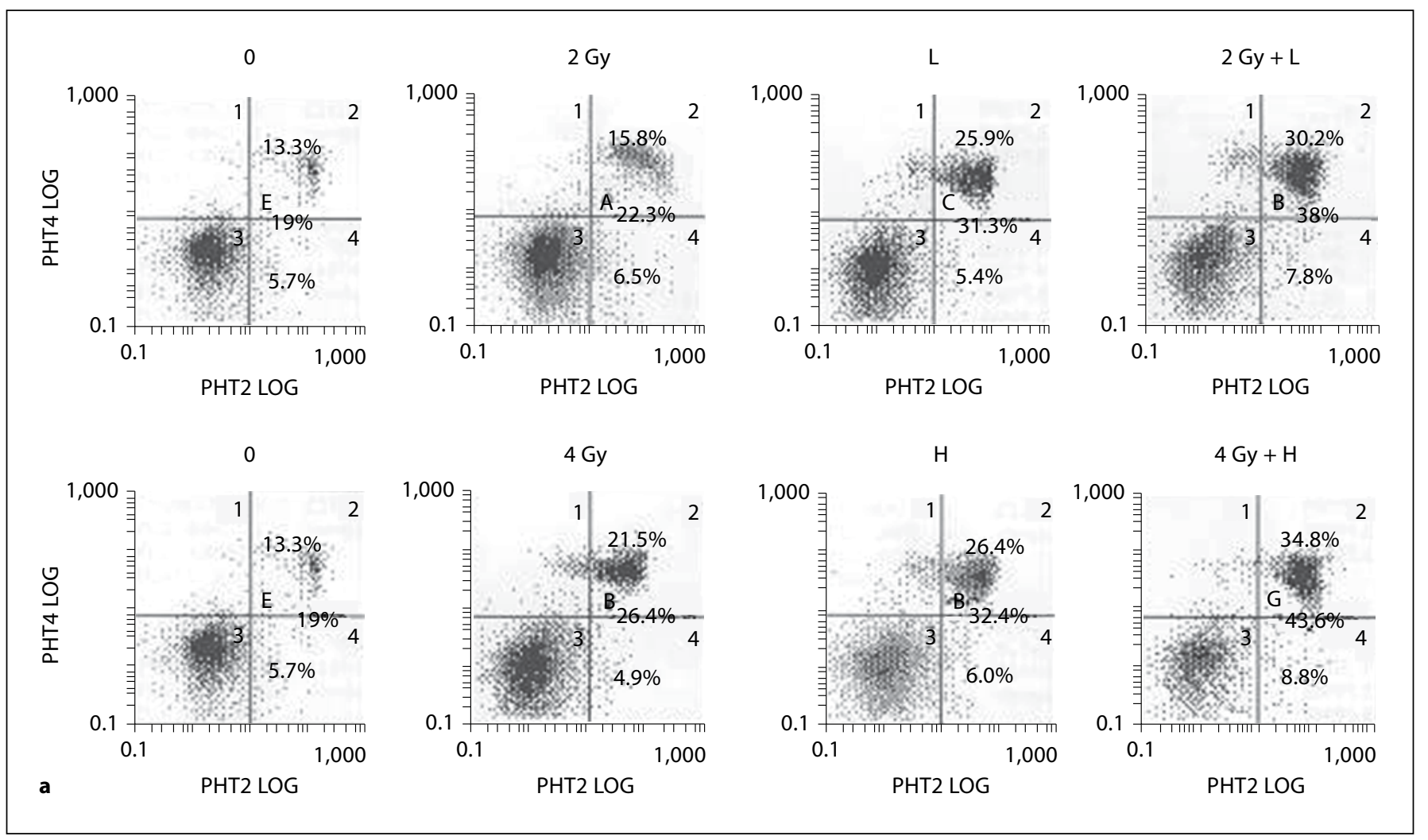

Fig. 5. Flow cytometric analysis of apoptosis in SW480 treated with chemotherapy and/or radiotherapy. SW480 cells were incubated for $48 \mathrm{~h}$ with different doses of chemotherapy and/or radiotherapy. Then, the cells were stained with both PI for total cell death (necrosis and apoptosis) and annexin $\mathrm{V}$ for apoptosis. $\mathrm{L}=$ Low concentration group of chemotherapy; $\mathrm{H}=$ high concentration group of chemotherapy. a Representative dot plots of annexin V/PI staining. The lower left quadrant contains the vital (double-negative) population. The lower right quadrant contains the early apoptotic (annexin V+/PI-) population, and the upper right quadrant contains the late apoptotic/necrotic (annexin $\mathrm{V}+/ \mathrm{PI}+$ ) population. $\mathbf{b}$ Data pooled from 3 independent experiments show the percentage of apoptotic cells. Difference was considered statistically significant when ${ }^{\mathrm{a}} \mathrm{p}<0.05$ and ${ }^{\mathrm{b}} \mathrm{p}<0.01$ versus control.

metric analysis was carried out to detect the fluorescence intensity of Rh123. As shown in figure 6b, treatment of SW480 cells with chemotherapy alone or radiotherapy alone at low or high concentrations caused a moderate depolarization of MMP. However, SW480 cells treated with CCR at either low or high concentrations (fig. 6) displayed a remarkable depolarization of MMP corresponding to a much higher fluorescence intensity compared with the control, suggesting the collapse of the inner mitochondrial membrane and mitochondrial dysfunction.

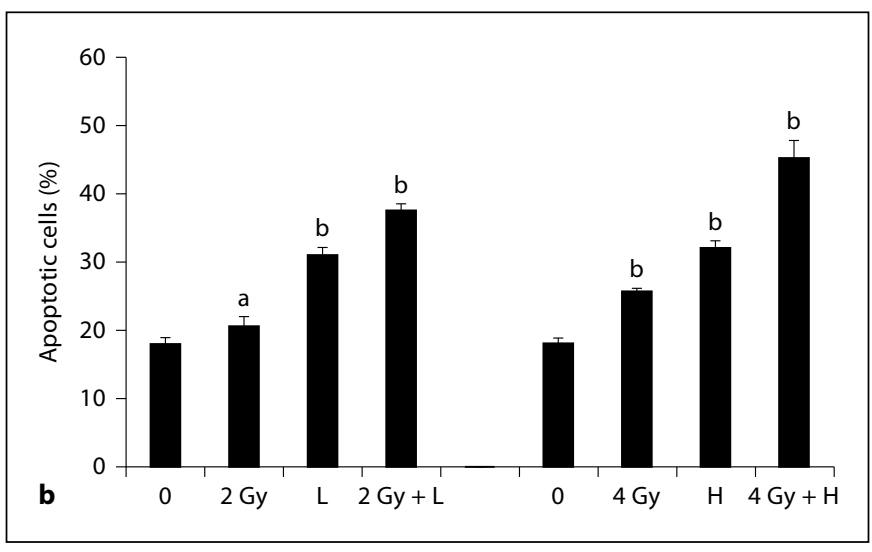

\section{Discussion}

BNIP3 is expressed at high levels in breast and ovarian cancers as well as in head and neck squamous cell carcinoma, but it is absent in many other tumors such as colorectal, stomach, pancreas and hematopoietic tumors $[13,14]$. Hypoxia can induce BNIP3L/NIX expression (the homologue of BNIP3) via a p53-dependent pathway [15].

The results of our experiment indicated that the expression of BNIP3 in colon cancer cells and CRC tissues was typically very low. However, its expression increased 


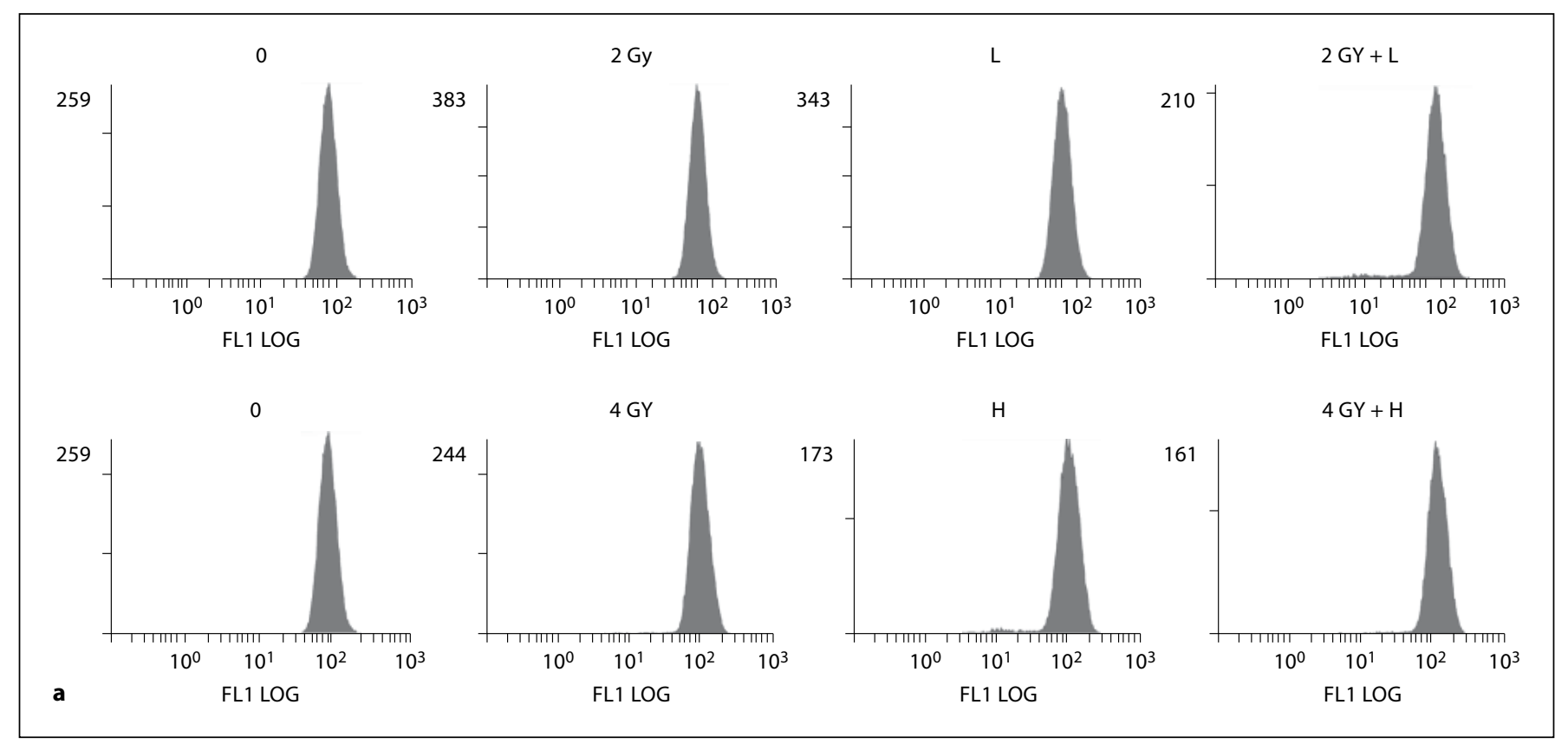

Fig. 6. Effects of chemotherapy and/or radiotherapy on the integrity of the mitochondrial membrane in SW480 cells. Cells were treated with different doses of chemotherapy and/or radiotherapy, then incubated with Rh123 and analyzed by flow cytometry. L = Low concentration group of chemotherapy; $\mathrm{H}=$ high concentration group of chemotherapy. a SW480 cells were treated with different doses of chemotherapy and/or radiotherapy for $48 \mathrm{~h}$. MMP was measured by Rh123, a fluorescent probe. Each test was performed 3 times, and images presented are typical of 3 independent experiments. b Data are presented as means \pm SD $(n=3)$. Difference was considered statistically significant when ${ }^{a} \mathrm{p}<0.05$ and ${ }^{\mathrm{b}} \mathrm{p}<0.01$ versus control.

following radiotherapy or chemotherapy $(\mathrm{p}<0.05)$ and was highest following CCR $(\mathrm{p}<0.05)$. In addition, we found that apoptosis increased along with the increased expression of BNIP3, suggesting that BNIP3 might be involved in the efficacy of radiotherapy and chemotherapy by promoting apoptosis. However, why the levels of BNIP3 in CRC are so low and by what molecular mechanisms radiotherapy and chemotherapy can upregulate its expression, is not yet understood.

It is know that p53 and Bcl-2 are involved in the development of colorectal neoplasia. As one of the downstream genes of $\mathrm{p} 53$, the proapoptotic BNIP3 protein might participate in the apoptotic process following chemotherapy and radiotherapy [15], during which BNIP3 forms heterodimers and interacts with antiapoptotic molecules Bcl2 or Bcl-xl. The heterodimer form of BNIP3 can prompt

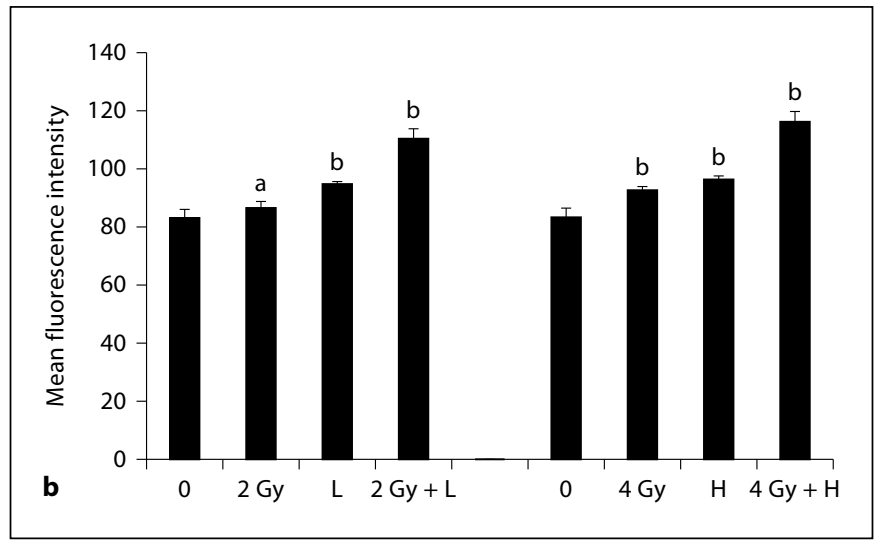

activated Bax and Bak to adhere to the outer mitochondrial membrane, forming a tetramer channel, which in turn precipitates the mitochondria to release cytochrome $\mathrm{c}$ and activate caspase-9-dependent apoptosis [16]. BNIP3 can also promote apoptosis via formation of the mitochondrial membrane permeability transition pore $[17,18]$. The tumor suppressor gene p53 and oncogene Bcl-2 have been confirmed to be mutations during the development of CRC. The mutation rate of the former was $50-80 \%$ and that of the latter 33-67\% [19]. Balcer-Kubiczek et al. [20] investigated the cytotoxicity of docetaxel (Taxotere) used as a single agent and in combination with radiation in human gastric, cervical and pancreatic cancer cells. They found that the combination of isoeffective concentrations of docetaxel with graded X-ray did result in either a moderate synergy or in additivity. However, the p53 status did 
not contribute directly to the effect of the drug alone or in combination with radiation. We regret that our experiments failed to detect the expression of the p53 gene. However, we studied the expression of the Bax gene as a putative downstream gene of p53 and found it had some opposite variation trend with BNIP3. Feng et al. [21] considered that $\mathrm{p} 53$ suppressed BNIP3 promoter activity efficiently under normoxic and hypoxic conditions. Our MMP test confirmed that radiotherapy and chemotherapy could induce potential cell membrane loss. Thus, BNIP3 may play a role in the caspase-dependent apoptosis pathways, mainly during treatment with chemotherapy and/or radiotherapy.

It is known that absent or low expression of BNIP3 is due to methylation at the $\mathrm{CpG}$ island and histidine $\mathrm{H} 3$ deacetylation within its promoter sequence $[22,23]$. DNA methylation can result in increased chromatin condensation and gene silencing [24]. Methylation is regulated by DNMTs [6]. In mammalian cells, DNMT1 is the primary methyltransferase $[25,26]$. Treatment with 5 -aza-dC can reverse methylation, allowing the expression of BNIP3 and subsequent increased tumor sensitivity to hypoxiainduced apoptosis [22, 24].

Most studies have confirmed that the BNIP3 protein is located in the outer mitochondrial membrane. However, Schmidt-Kastner et al. [27] observed the expression of BNIP3 in the nucleus of rat hippocampal neurons and, under hypoxic conditions, these cells sustained injury as a result of BNIP3 translocation into the cytoplasm. Burton et al. [28] observed that in normal brain cells, BNIP3 was located in the nucleus and was translocated into the cytoplasm during hypoxia, thus promoting apoptosis. However, in pleomorphic glial blastoma cells, BNIP3 is always observed in the nucleus regardless of hypoxic conditions. This inability to translocate into the cytoplasm may be related to the lack of apoptosis in some tumor tissues that express high levels of BNIP3. In addition, BNIP3 is located in the nucleus of auricular cartilage cells. Although there is poor blood and oxygen supply (abundant hypoxia-inducible factor 1), BNIP3 cannot play the role of apoptosis, suggesting that BNIP3 translocation into the nucleus may be one mechanism by which cells evade apoptosis [29].

Accordingly, we suspected that the low expression of BNIP3 in CRC may be a result of (1) insufficient hypoxia causing BNIP3 to translocate from the nucleus to the cytoplasm or something else, preventing BNIP3 from effectively combining with hypoxia-inducible factor 1, or (2) BNIP3 being transferred into intranuclear or (3) aberrant methylation in the promoter region of BNIP3, preventing its expression. We studied the third possibility further by exploring the relationship between methylation and radiotherapy and/or chemotherapy. Our research showed that the expression and activity of DNMT in colon cancer cells in the absence of radiotherapy and chemotherapy were higher than in the presence of these treatments, with the lowest expression observed following CCR $(\mathrm{p}<0.05)$. In contrast, the expression of BNIP3 was shown to be in inverse proportion to that of DNMT under the same conditions. We considered that chemotherapy and radiotherapy might remove BNIP3 promoter methylation by inhibiting the expression and activity of DNMT, restoring BNIP3 expression and promoting apoptosis. Nevertheless, a recent report on 195 cases showed that the poor prognosis of CRC patients with hypoxia-inducible factor$2 \alpha$ or carbonic anhydrase 9 was related to the expression of TP53 ( $\mathrm{p}=0.001$ and 0.0391 , respectively) but not to BNIP3 methylation [30]. Therefore, we believe that BNIP3 silencing induced by methylation can affect both treatment and prognosis of tumors, but the degree of this effect, the mechanisms required and other genes or relevant factors involved remain to be elucidated.

In summary, we confirmed that radiotherapy and chemotherapy could kill tumor cells by promoting apoptosis. This was achieved via downregulation of DNMT expression/activity and the upregulation of BNIP3 following demethylation of its promoter region. This study provided a biological basis for the use of CCR for the treatment of CRC and also established a basis for targeting BNIP3 in future clinical treatments.

\section{Acknowledgements}

We thank Li Li, MM, Xiao-dong Wang, MM and Wen Zhang, $\mathrm{MM}$, for collecting the patient specimens for this study.

\section{Disclosure Statement}

The authors declare no competing financial interests.

$\begin{aligned} & \text { References } \text { Chen YC, Hunter DJ: Molecular epidemiol- } \\ & \text { ogy of cancer. CA Cancer J Clin 2005; 55:45- } \\ & 54 \text { - }\end{aligned}$

Deng/Huang/Chen/Li/Wang/Zhang/Bi/ Tang/Li/Wang 
4 Yasuda M, Theodorakis P, Subramanian T, et al: Adenovirus E1B-19K/BCL-2 interacting protein BNIP3 contains a $\mathrm{BH} 3$ domain and a mitochondrial targeting sequence. J Biol Chem 1998;273:12415-12421.

5 Ray R, Chen G, Vande Velde C, et al: BNIP3 heterodimerizes with $\mathrm{Bcl}-2 / \mathrm{Bcl}-\mathrm{X}(\mathrm{L})$ and induces cell death independent of a Bcl-2 homology $3(\mathrm{BH})$ domain at both mitochondrial and nonmitochondrial sites. J Biol Chem 2000;275:1439-1448.

-6 Yamashita S, Tsujino Y, Moriguchi K, et al: Chemical genomic screening for methylation-silenced genes in gastric cancer cell lines using 5-aza-2'-deoxycytidine treatment and oligonucleotide microarray. Cancer Sci 2006 97:64-71.

7 Murai M, Toyota M, Suzuki H, et al: Aberrant methylation and silencing of the BNIP3 gene in colorectal and gastric cancer. Clin Cancer Res 2005;11:1021-1027.

$\checkmark 8$ Yuan RH, Jeng YM, Pan HW, et al: Overexpression of KIAA0101 predicts high stage, early tumor recurrence, and poor prognosis of hepatocellular carcinoma. Clin Cancer Res 2007;13:5368-5376.

-9 Zolk O, Solbach TF, Eschenhagen T, et al: Activation of negative regulators of the hypoxiainducible factor (HIF) pathway in human end-stage heart failure. Biochem Biophys Res Commun 2008;376:315-320.

10 Bai ZY, Xu GB, Wu SL: Detection of DNAmethyltransferase activity of leukemia cells with radiology microassay. J Bei Jing Med Univ 2000;32:76-78.

11 Nakazato T, Sagawa M, Yamato K, et al: Myeloperoxidase is a key regulator of oxidative stress mediated apoptosis in myeloid leukemic cells. Clin Cancer Res 2007;13:54365445.

12 Gong Y, Han XD: Nonylphenol-induced oxidative stress and cytotoxicity in testicular Sertoli cells. Reprod Toxicol 2006;22:623-630.
13 Sowter HM, Ratcliffe PJ, Watson P, et al: HIF1-dependent regulation of hypoxic induction of cell death factors BNIP3 and NIX in human tumors. Cancer Res 2001;61:6669-6673.

$\checkmark 14$ Sowter HM, Ferguson M, Pym C, et al: Expression of the cell death gene BNip3 and NIX in ductal carcinoma in situ of the breast; correlation of BNip3 levels with necrosis and grade. J Pathol 2003;201:573-580.

15 Fei P, Wang W, Kim SH, et al: Bnip3L is induced by p 53 under hypoxia, and its knockdown promotes tumor growth. Cancer Cell 2004;6:597-609.

16 Van Loo G, Saelens X, van Gurp M, et al: The role of mitochondrial factors in apoptosis: a Russian roulette with more than one bullet. Cell Death Differ 2002;9:1031-1042.

17 Vande Velde C, Cizeau J, Dubik D, et al: BNIP3 and genetic control of necrosis-like cell death through the mitochondrial permeability transition pore. Mol Cell Biol 2000;20: 5454-5468.

18 Regula KM, Ens K, Kirshenbaum LA: Inducible expression of BNip3 provokes mitochondrial defects and hypoxia-mediated cell death of ventricular myocytes. Circ Res 2002;91: 226-231.

19 Yan J, Yun H, Yang Y, et al: Upregulation of BNIP3 promotes apoptosis of lung cancer cells that were induced by p53. Biochem Biophys Res Commun 2006;346:501-507.

20 Balcer-Kubiczek EK, Attarpour M, Jiang J, et al: Cytotoxicity of docetaxel (Taxotere) used as a single agent and in combination with radiation in human gastric, cervical and pancreatic cancer cells. Chemotherapy 2006;52:231240.

21 Feng X, Liu X, Zhang W, et al: p53 directly suppresses BNIP3 expression to protect against hypoxia-induced cell death. EMBO J 2011;30:3397-3415.
22 Murai M, Toyota M, Satoh A, et al: Aberrant DNA methylation associated with silencing BNIP3 gene expression in haematopoietic tumours. Br J Cancer 2005;92:1165-1172.

23 Abe T, Toyota M, Suzuki H, et al: Upregulation of BNIP3 by 5-aza-2'-deoxycytidine sensitizes pancreatic cancer cells to hypoxia-mediated cell death. J Gastroenterol 2005;40: 504-510.

24 Ehrlich M, Buchanan KL, Tsien F, et al: DNA methyltransferase $3 \mathrm{~B}$ mutations linked to the ICF syndrome cause dysregulation of lymphogenesis genes. Hum Mol Genet 2001;10: 2917-2931.

25 Wade PA: Methyl CpG-binding proteins and transcriptional repression. Bioessays 2001;23: 1131-1137.

26 Jackson-Grusby L, Beard C, Possemato R, et al: Loss of genomic methylation causes p53dependent apoptosis and epigenetic deregulation. Nat Genet 2001;27:31-39.

-27 Schmidt-Kastner R, Aguirre-Chen C, Kietzmann T, et al: Nuclear localization of the hypoxia-regulated pro-apoptotic protein BNIP3 after global brain ischemia in the rat hippocampus. Brain Res 2004;1001:133-142.

28 Burton TR, Henson ES, Baijal P, et al: The pro-cell death Bcl-2 family member, BNIP3, is localized to the nucleus of human glial cells: implications for glioblastoma multiforme tumor cell survival under hypoxia. Int J Cancer 2006;118:1660-1669.

29 Giatromanolaki A, Koukourakis MI, Sower $\mathrm{HM}$, et al: BNIP3 expression is linked with hypoxia-regulated protein expression and with poor prognosis in non-small cell lung cancer. Clin Cancer Res 2004;10:5566-5571.

30 Cleven AH, Wouters BG, Schutte B, et al: Poorer outcome in stromal HIF-2 alpha-and CA9-positive colorectal adenocarcinomas is associated with wild-type TP53 but not with BNIP3 promoter hypermethylation or apoptosis. Br J Cancer 2008;99:727-733. 